Research Article

\title{
Oxidation Mechanism of Biomedical Titanium Alloy Surface and Experiment
}

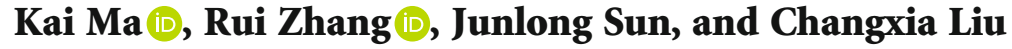 \\ College of Transportation, Ludong University, Shandong, China 264025 \\ Correspondence should be addressed to Rui Zhang; 3299@ldu.edu.cn
}

Received 27 March 2020; Revised 11 June 2020; Accepted 8 July 2020; Published 13 August 2020

Academic Editor: Michael J. Schütze

Copyright (C) 2020 Kai Ma et al. This is an open access article distributed under the Creative Commons Attribution License, which permits unrestricted use, distribution, and reproduction in any medium, provided the original work is properly cited.

\begin{abstract}
The biological activity, biocompatibility, and corrosion resistance of implants depend primarily on titanium dioxide $\left(\mathrm{TiO}_{2}\right)$ film on biomedical titanium alloy (Ti6Al4V). This research is aimed at getting an ideal temperature range for forming a dense titanium dioxide $\left(\mathrm{TiO}_{2}\right)$ film during titanium alloy cutting. This article is based on Gibbs free energy, entropy changes, and oxygen partial pressure equations to perform thermodynamic calculations on the oxidation reaction of titanium alloys, studies the oxidation reaction history of titanium alloys, and analyzes the formation conditions of titanium dioxide. The heat oxidation experiment was carried out. The chemical composition was analyzed with an energy dispersive spectrometer (EDS). The results revealed that titanium dioxide $\left(\mathrm{TiO}_{2}\right)$ is the main reaction product on the surface below $900^{\circ} \mathrm{C}$. Excellent porous oxidation films can be obtained between $670^{\circ} \mathrm{C}$ and $750^{\circ} \mathrm{C}$, which is helpful to improve the bioactivity and osseointegration of implants.
\end{abstract}

\section{Introduction}

Titanium alloy is widely used as a biomaterial due to its superior biocompatibility, mechanical properties close to human bones, and enhanced corrosion resistance. These properties have made the alloys suitable for use in a wide spectrum of biomedical applications including artificial bones, artificial joints, dental roots, and medical devices. The excellent performance of titanium alloy is mainly due to the oxide film as shown in Figure 1 [1]. The functional composition of the oxide film is mainly titanium dioxide $\left(\mathrm{TiO}_{2}\right)$. Titanium dioxide has good biocompatibility, stable chemical property, and low solubility in water, which prevents substrate metal ions from dissolution. Furthermore, it also improves the wear and fatigue resistance of implants in the human body.

The conventional surface treatment methods of titanium alloy include glow discharge plasma deposition, oxygen ion implantation, hydrogen peroxide treatment, thermal oxidation, sol-gel method, anodic oxidation, microarc oxidation, laser alloying, and pulsed laser deposition. These methods have different characteristics and are applied in different fields. Glow discharge plasma deposition can get a clean surface, and the thickness of the oxide film obtained is $2 \mathrm{~nm}$ to $150 \mathrm{~nm}$ [2-8]. The oxide film obtained from oxygen ion implantation is thicker, about several microns [9-14]. Hydrogen peroxide treatment of titanium alloy surface is a process of chemical dissolution and oxidation $[15,16]$. The dense part of the oxide film is less than $5 \mathrm{~nm}$ [17-21]. The oxide film generated from the thermal oxidation method has a porous structure, and its thickness is commonly about $10-20 \mu \mathrm{m}$ [22-25]. The oxide film from the sol-gel method is rich in $\mathrm{Ti}-\mathrm{OH}$, a composition that could induce apatite nucleation and improve the combining of implants and bone. It has a thickness of less than $10 \mu \mathrm{m}$ [26-28]. Applied with the anodic oxidation method, the surface can generate a porous oxide film of $10 \mu \mathrm{m}$ to $20 \mu \mathrm{m}$ thickness [29-31]. Similarly, the oxide film generated from the microarc oxidation method is also porous and has a thickness of $10 \mu \mathrm{m}$ to $20 \mu \mathrm{m}[32,33]$.

Unfortunately, we studied that all of the above methods are employed after machining or forming, and they require a long process chain and costly production types of equipment [21-24]. Therefore, we proposed a titanium alloy implant preparation process that integrated with cutting and surface modification. The oxygen-rich atmosphere increases the partial pressure of oxygen in the oxidizing 


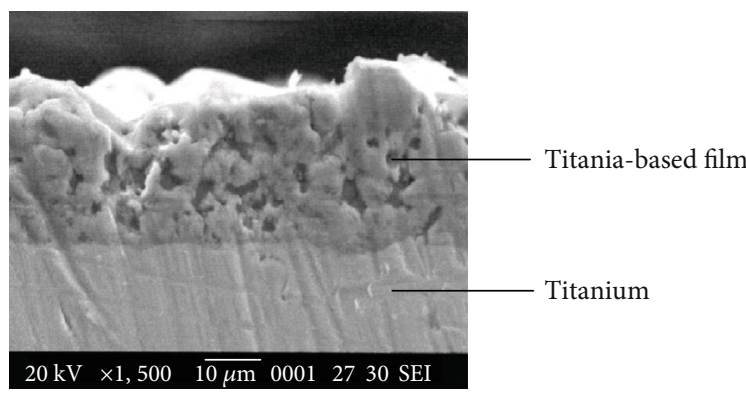

Figure 1: Cross-sectional view of the microarc oxidation sample.

environment, and the heat generated during the cutting process increases the temperature and the rate of the oxidation. It uses the cutting heat and oxygen-rich atmosphere generated during the cutting process to form the oxide film $\left(\mathrm{TiO}_{2}\right)$ to improve the corrosion resistance of the titanium alloy. The experimental equipment is shown in Figure 2. Since the cutting temperature is the most important factor in the oxide film formation process, this paper carried out researches based on theoretical analysis and experimental investigation to acquire an ideal temperature range for the cutting process to achieve the oxide layer.

\section{Oxidation Mechanism of Titanium Alloy}

2.1. Thermodynamic Analysis of Titanium Alloy Oxidation Reaction. Thermodynamics is mainly used in studying reaction balance and energy balance in chemistry. Data calculated by thermodynamics can reveal the moving direction of chemical equilibrium and energy balance. The oxidation of titanium alloy has several possible reactions under different conditions:

$$
\begin{aligned}
\text { Reaction } 1: 3 \mathrm{Ti}+\frac{5}{2} \mathrm{O}_{2} & =\mathrm{Ti}_{3} \mathrm{O}_{5} \\
\text { Reaction } 2: 2 \mathrm{Ti}+\frac{3}{2} \mathrm{O}_{2} & =\mathrm{Ti}_{2} \mathrm{O}_{3} \\
\text { Reaction } 3: \mathrm{Ti}+\mathrm{O}_{2} & =\mathrm{TiO}_{2 \text { (rutilen) }} \\
\text { Reaction } 4: \mathrm{Ti}+\mathrm{O}_{2} & =\mathrm{TiO}_{2} \text { (anatase) } \\
\text { Reaction } 5: \mathrm{Ti}+\frac{1}{2} \mathrm{O}_{2} & =\mathrm{TiO} \\
\text { Reaction } 6: \mathrm{TiO}+\frac{1}{2} \mathrm{O}_{2} & =\mathrm{TiO}_{2} \\
\text { Reaction } 7: \frac{1}{2} \mathrm{Ti}_{2} \mathrm{O}_{3}+\frac{1}{4} \mathrm{O}_{2} & =\mathrm{TiO}_{2} \\
\text { Reaction } 8: \frac{1}{3} \mathrm{Ti}_{3} \mathrm{O}_{5}+\frac{1}{6} \mathrm{O}_{2} & =\mathrm{TiO}_{2}
\end{aligned}
$$

For the different reaction equations, the condition of limits and temperature range of reaction are different. To determine the reaction temperature range, Gibbs free energy, entropy changes, and oxygen partial pressure equations are usually used in the calculations $[34,35]$ as follows:

$$
\begin{aligned}
\Delta G_{T}^{\Theta} & =\Delta H_{298}^{\Theta}-T \Delta \varphi_{T}^{\prime}, \\
\Delta S_{T}^{\Theta} & =\Sigma\left(n_{i} S_{i, T}^{\Theta}\right)_{\text {product }}-\Sigma\left(n_{i} S_{i, T}^{\Theta}\right)_{\text {reactant }} \\
\Delta G_{T}^{\Theta} & =R T \ln \mathrm{PO}_{2}^{*},
\end{aligned}
$$

where $\Delta G_{T}^{\Theta}$ is standard Gibbs free energy; $\Delta H_{298}^{\Theta}$ is the standard enthalpy of reaction; $\Delta \varphi_{T}^{\prime}$ is the reaction Gibbs free energy function; $\Delta S_{T}^{\Theta}$ is the standard reaction entropy difference; $S_{i, T}^{\Theta}$ is standard molar entropy of pure substance $i$ at temperature $T$; $R$ is the gas constant; $T$ is reaction temperature; and $\mathrm{PO}_{2}^{*}$ is standard equilibrium oxygen partial pressure of reaction.

It can be observed from Figure 3 that the Gibbs free energy values of these 8 reactions are negative. So, oxidation of titanium alloy is a spontaneous reaction. With the lower value of Gibbs free energy, an easier reaction could occur. The Gibbs free energy in reaction (1) is the minimum, where the $\mathrm{Ti}_{3} \mathrm{O}_{5}$ composition is generated. The values of Gibbs free energy increase from reaction (1) to reaction (5). The productions of these reactions, respectively, are $\mathrm{Ti}_{3} \mathrm{O}_{5}, \mathrm{Ti}_{2} \mathrm{O}_{3}$, $\mathrm{TiO}_{2}$, and $\mathrm{TiO}$ according to the reactivity of titanium. However, the final products are determined by two major factors, temperature and oxygen partial pressure. Although $\mathrm{Ti}_{3} \mathrm{O}_{5}$ and $\mathrm{Ti}_{2} \mathrm{O}_{3}$ are more stable than $\mathrm{TiO}_{2}$ based on thermodynamics theory, the oxidation products mainly are $\mathrm{TiO}_{2}$ on the surface of titanium alloy when the cutting temperature is less than $1000^{\circ} \mathrm{C}$ [36]. The titanium ions in $\mathrm{Ti}_{3} \mathrm{O}_{5}$ and $\mathrm{Ti}_{2} \mathrm{O}_{3}$ are at intermediate valence state and can be further oxidized to the highest valence state in the atmosphere [37].

Figure 4 shows standard reaction entropy difference curves. It can be observed that the $\mathrm{TiO}_{2}$ is generated in reactions (3), (6), (7) and (8). But there are differences in standard entropy change among these reactions. It can be seen from Figure 4 that compared with $\mathrm{Ti}_{2} \mathrm{O}_{3}$ and $\mathrm{TiO}$, the absolute value of the standard entropy difference of $\mathrm{Ti}_{2} \mathrm{O}_{5}$ oxidation to $\mathrm{TiO}_{2}$ is the smallest, which means that the required entropy change is the smallest. Low-valence oxides $\left(\mathrm{Ti}_{3} \mathrm{O}_{5}\right.$, $\mathrm{Ti}_{2} \mathrm{O}_{3}$, and $\mathrm{TiO}$ ) are easier to be oxidized to $\mathrm{TiO}_{2}$ than titanium. With the increase of temperature, the entropy change (absolute value) required for low-valence oxide becomes bigger. When the temperature is higher, the low-valence oxide becomes more stable. Equation (11) is the oxygen partial pressure calculation formula, where $\mathrm{PO}_{2}^{*}$ is the standard equilibrium oxygen partial pressure. It represents the trend of oxygen escaped from the oxide. When the oxygen partial pressure of the gaseous phase is lower than the equilibrium oxygen partial pressure, oxide could not keep stable and began to decompose. On the contrary, the oxide would keep stable. As the standard equilibrium oxygen partial pressure gets higher, the oxide becomes easier to decompose.

As shown in Figure 5, oxygen partial pressure increases with temperature, and the oxygen partial pressure of titanium oxidation is $0.0035 \mathrm{MPa}$ which is lower than $0.02 \mathrm{MPa}$ at the oxidizing temperature of $1227^{\circ} \mathrm{C}(1500 \mathrm{~K})$; $\mathrm{TiO}_{2}$ would not decompose. Therefore, at the temperature below $1227^{\circ} \mathrm{C}$, the main oxidation products of titanium alloy are $\mathrm{TiO}_{2}$. 


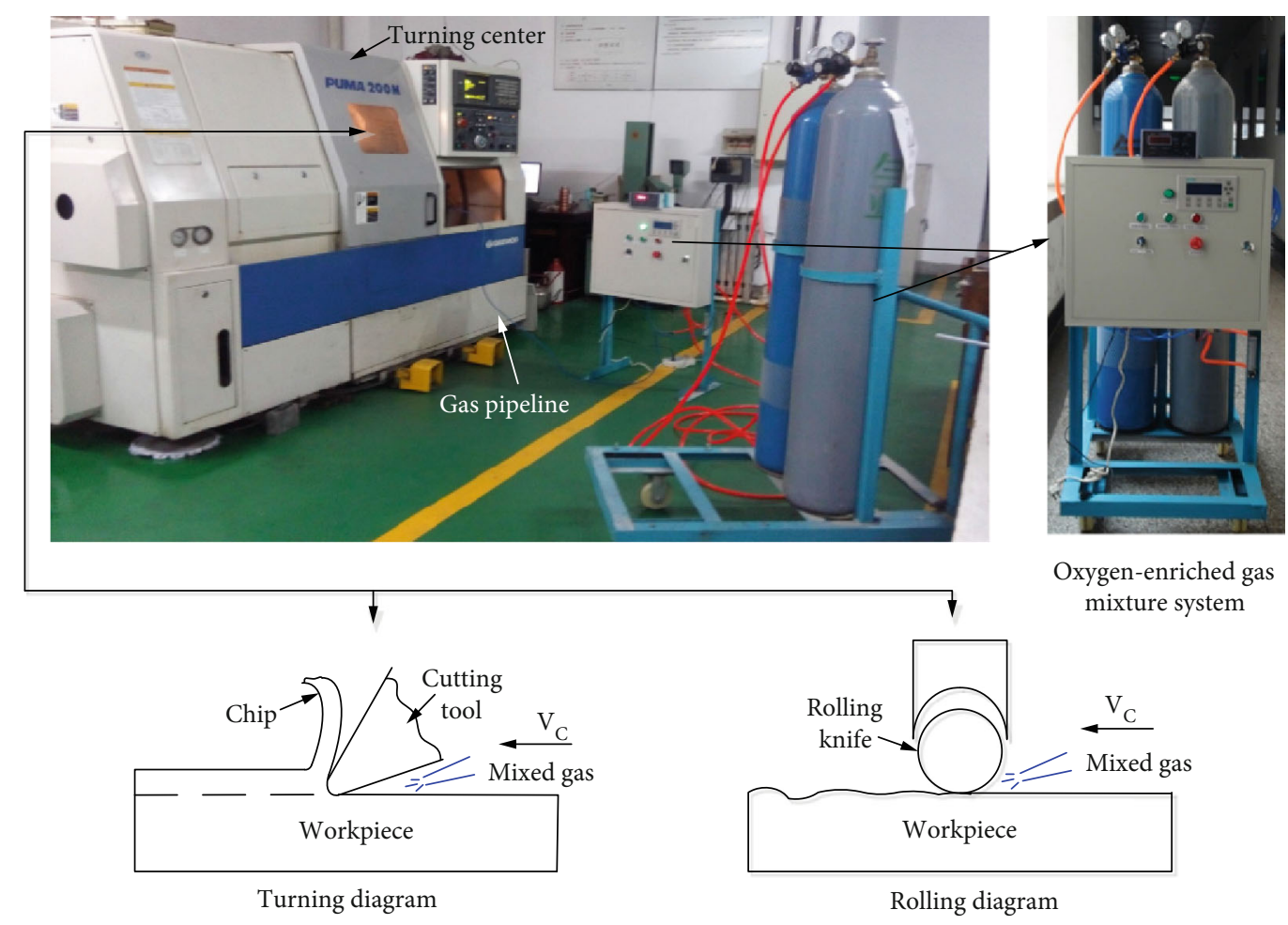

FIGURE 2: Experimental device for turning and rolling in an oxygen-enriched atmosphere.

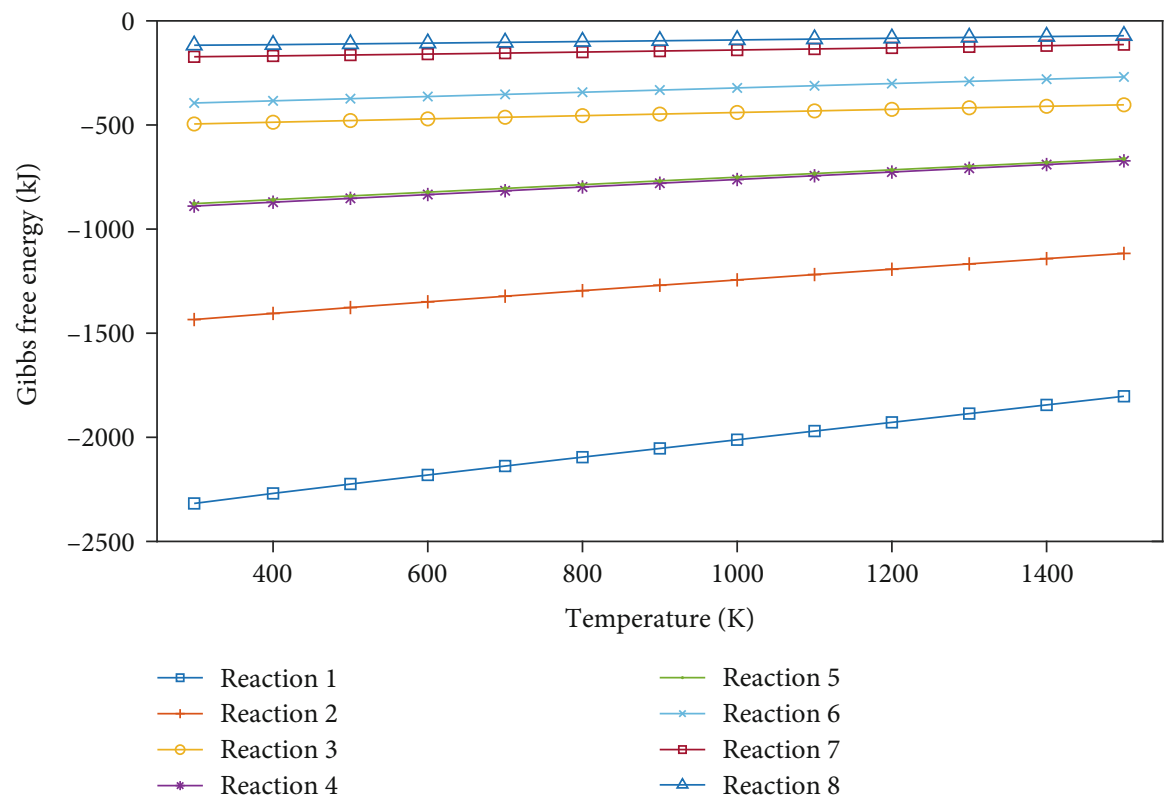

Figure 3: Variation of Gibbs free energy at different temperatures.

2.2. The Kinetic Reaction Mechanism of Titanium Alloy Oxidation. The process of titanium oxidation is determined by the reactions between titanium and oxygen on the surface layer. The titanium oxidation process includes two aspects: oxygen vacancy diffusion through the anionic oxide layer and the instability and decomposition of $\mathrm{TiO}_{2}$ on the surface layer [38]. A large amount of oxygen can dissolve in titanium. However, the diffusion of oxygen to the titanium substrate is slower [39]. The oxygen content at the interface between the oxidized layer and the titanium substrate is lower. Oxidation rate can be improved by increasing oxygen concentration and temperature, for they are two major factors that influence the oxidation rate. Higher oxygen concentration makes titanium oxidation diffuse further in the depth direction. The activity of titanium atoms on the surface increased as the temperature gets higher. The higher temperature also 


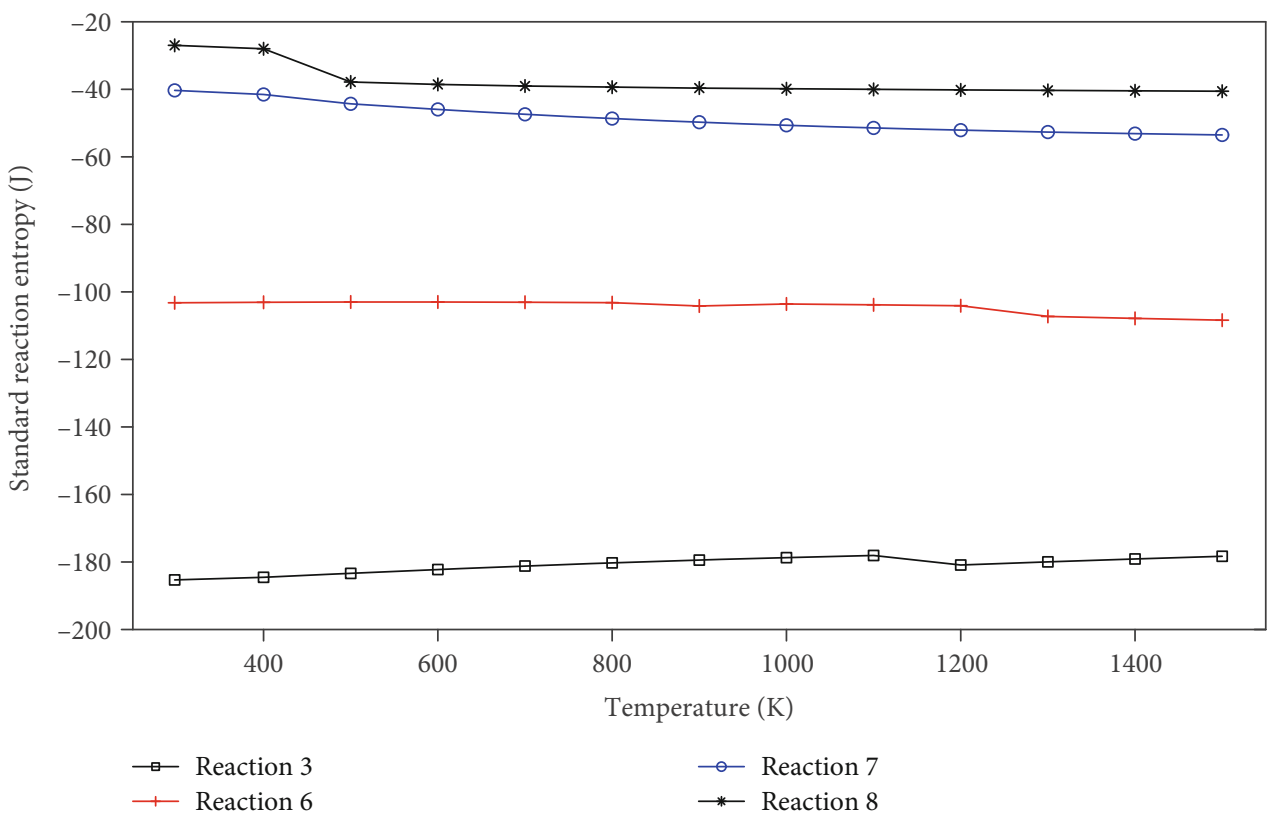

FIGURE 4: Standard reaction entropy difference at different temperatures.

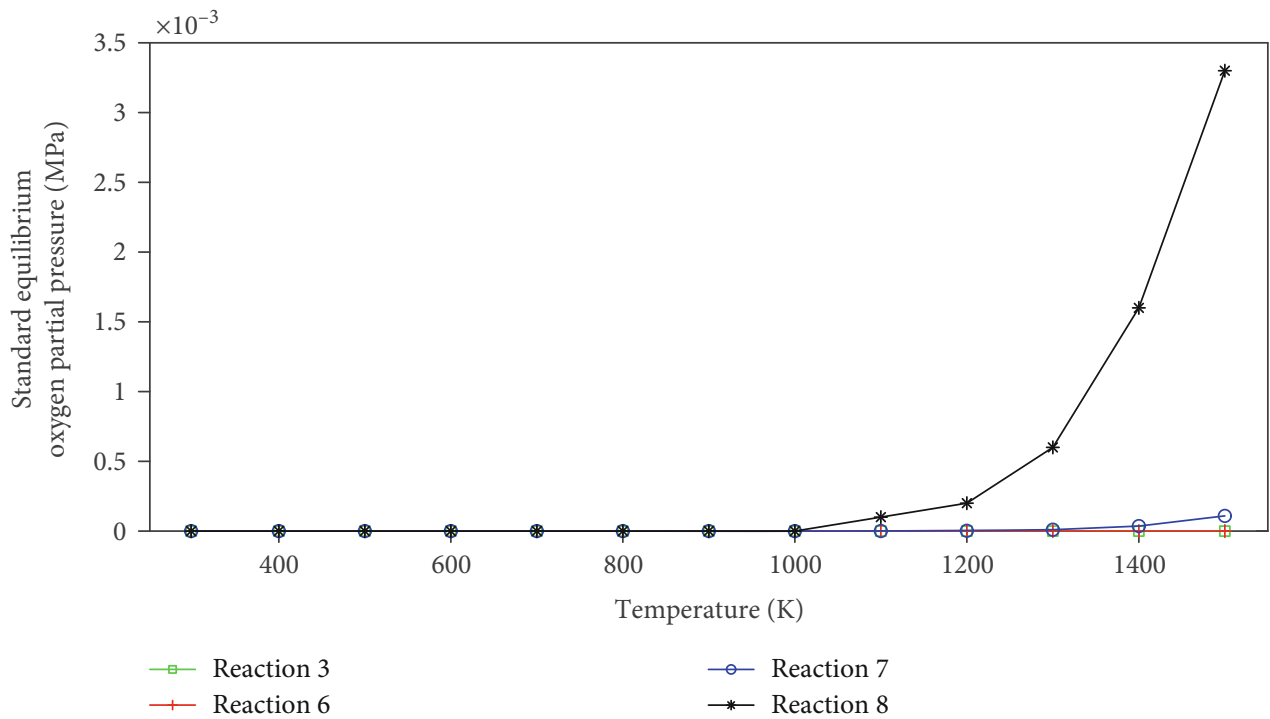

FIGURE 5: Standard equilibrium oxygen partial pressure at different temperatures.

improves the diffusion rate of oxygen atoms and titanium atoms in the oxide layer. At room temperature, the oxidation forms a thin oxide layer on titanium surface at first, and the oxide layer becomes porous when it is thick enough. Titanium obviously is oxidized when the temperature is above $600^{\circ} \mathrm{C}$. The oxygen diffusion in titanium is quicker, and the oxidation is more fierce when the temperature is between $700^{\circ} \mathrm{C}$ and $800^{\circ} \mathrm{C}$ [39].

The oxidation kinetics of titanium alloy is a theory about reaction rate and diffusion speed. The thermodynamic function can provide a profile of reaction possibilities, spontaneous tendencies, and reaction direction from the state stability variation in reaction. The thermodynamic function does not refer to the oxide reaction process of titanium, nor does the movement and chemical activity of titanium atoms and oxygen atoms. In thermodynamics theory, when the temperature is higher, the standard equilibrium oxygen partial pressure increases, and the decomposition of oxide becomes easier. The oxide starts to break down when the standard equilibrium oxygen partial pressure becomes larger in the oxidation environment. However, the oxidation rate (forward) and decomposition rate (backward) of oxidation products both increase with the temperature. The decomposition speed is equal to the oxidation rate when the Gibbs free energy gets to zero. The decomposition speed is larger than the oxidation rate when the Gibbs free energy is above zero, 

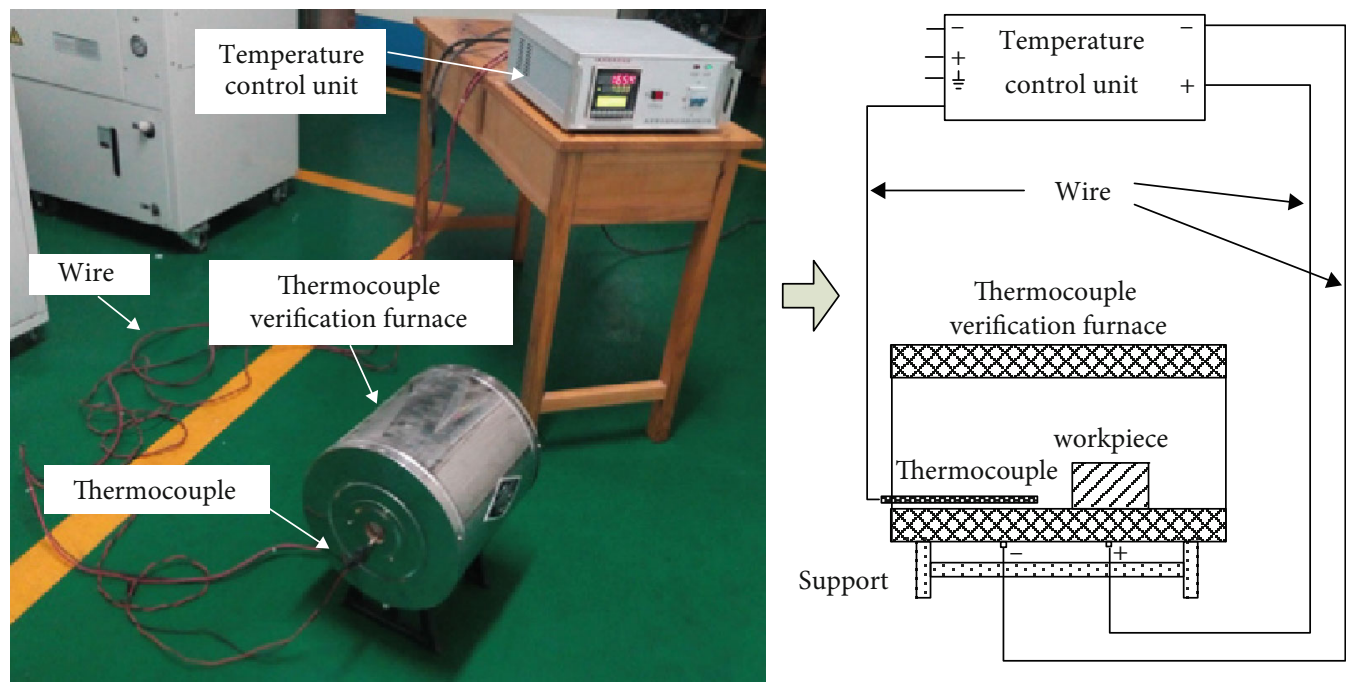

FIGURE 6: Heating furnace and temperature control system.

and the forward reaction would not occur spontaneously. Thermodynamics can be used in judging reaction tendencies when reaction approaches equilibrium at a certain temperature. However, it cannot describe the oxidation rate. In contrast, the kinetic reaction mechanism can describe the oxidation rate and cannot judge reaction tendency. So, these theories reveal the oxidation mechanism from different aspects. With the temperature increases, the decomposition of oxide is possible. Therefore, at the temperature below $1227^{\circ} \mathrm{C}$, a higher temperature is helpful for titanium alloy oxidation, and the main oxidation products in this process are $\mathrm{TiO}_{2}$.

\section{Experimental Work}

3.1. Materials and Methods. Ti6Al4V rods were used in the experiments. The diameter of these Ti6Al4V rods is $14 \mathrm{~mm}$, and the length of rods is $5 \mathrm{~mm}$. The Ti6Al4V samples should be polished to the same surface roughness and then ultrasonically cleaned in acetone and absolute ethanol for ten minutes. The rods were heated in the furnace (Figure 6) to an initial temperature of $400^{\circ} \mathrm{C}$. Above $400^{\circ} \mathrm{C}$, different specimens were heated at intervals of $50^{\circ} \mathrm{C}$. The rods were oxidized in static air with three oxidation times of $5 \mathrm{~min}$, $10 \mathrm{~min}$, and $15 \mathrm{~min}$. The oxidized samples were observed using an energy dispersive spectrometer (EDS). The results obtained are discussed in the next section.

\subsection{Results and Analysis}

3.2.1. EDS Analysis of Oxide Layers. The EDS analysis of oxide layers at different temperatures and time is shown in Figure 7. The substrate elements ( $\mathrm{Ti}, \mathrm{Al}$, and $\mathrm{V}$ ) and oxygen element were detected by EDS when the temperature was lower than $800^{\circ} \mathrm{C}$. The oxygen mainly appeared in the spectrum above $800^{\circ} \mathrm{C}$; those oxygen content in the oxide layer significantly increased. It showed a significant increase in diffusion of oxygen in the oxide layer. The reaction of titanium and oxygen gets obvious. As illustrated in Figure 8, as the oxidation temperature gets higher, the content of oxygen in the oxide layer becomes higher. Within the range of temperatures used here, it can be observed that as the temperature increases, the curve of oxygen content follows a parabolic curve. Furthermore, at the same oxidation temperature of $650^{\circ} \mathrm{C}$, the oxygen element content of the oxide film layer is different at different oxidation times. It indicated that the longer oxidation time results in higher oxygen content.

\section{The Influence of $\mathrm{N}, \mathrm{H}, \mathrm{Al}, \mathrm{V}$, and $\mathrm{Ti}$ on the Composition of Oxide Layers}

The main compositions of Ti6Al4V are $\mathrm{Ti}, \mathrm{Al}$, and $\mathrm{V}$. Therefore, when titanium alloy is heated in the air, titanium is also prone to react with the $\mathrm{N}_{2}, \mathrm{H}_{2}$, and $\mathrm{O}_{2}$. Aluminum and vanadium will also react with the oxygen. The Gibbs free energy curves are shown in Figure 9. The reaction equations are as follows:

$$
\begin{array}{r}
\text { Reaction 9: } \mathrm{Ti}+\frac{1}{2} \mathrm{~N}_{2}=\mathrm{TiN} \\
\text { Reaction } 10: \mathrm{Ti}+\mathrm{H}_{2}=\mathrm{TiH}_{2} \\
\text { Reaction } 11: 2 \mathrm{Al}+\frac{3}{2} \mathrm{O}_{2}=\mathrm{Al}_{2} \mathrm{O}_{3} \\
\text { Reaction } 12: 2 \mathrm{~V}+\frac{5}{2} \mathrm{O}_{2}=\mathrm{V}_{2} \mathrm{O}_{5}
\end{array}
$$

4.1. The Reaction between Titanium and Hydrogen. As shown in Figure 9, the Gibbs free energy of titanium reaction with hydrogen is the highest value, so it is not easy for titanium to react with hydrogen. Because the Gibbs free energy is negative below $650^{\circ} \mathrm{C}$, the reaction of titanium and hydrogen can be spontaneous only in this condition. Besides, the existence of the oxide layer will decrease the hydrogen absorption rate of titanium alloy. For example, the oxide layer with the thickness that is less than $0.45 \mu \mathrm{m}$ can reduce the hydrogen absorption rate to one-fourth of its original value [38]. 

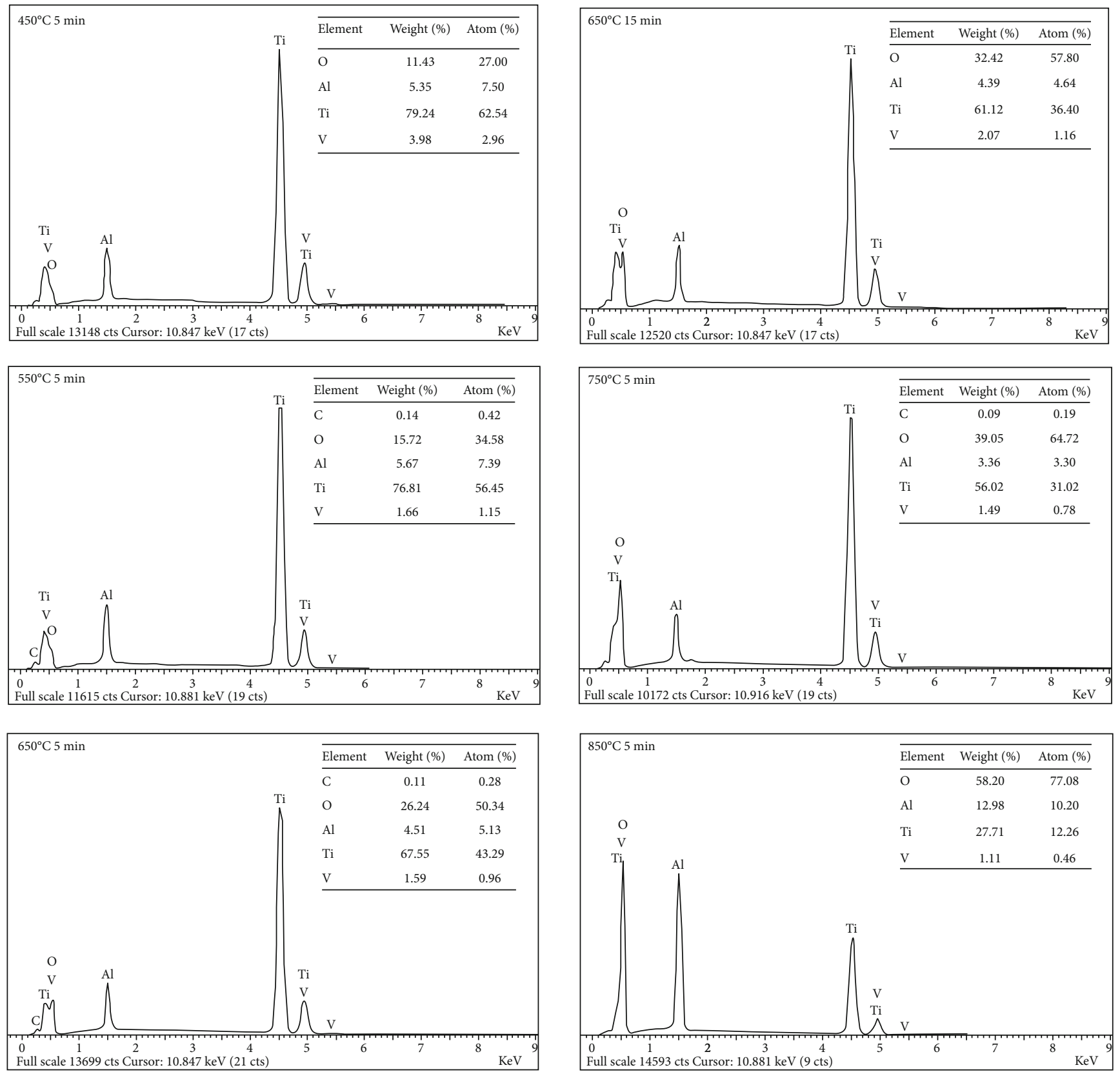

FIGURE 7: EDS analysis of oxide layers at different temperatures and time.

However, the existence of titanium hydride will lead to the expansion of the oxide layer due to hydrogen dissolving. Therefore, it can be concluded that to get the compact oxide layer and avoid the generation of titanium hydride, the heating temperature of titanium should be higher than $650^{\circ} \mathrm{C}$.

\subsection{The Reaction between Titanium and Nitrogen. From the} values of Gibbs free energy, it can be deduced that the oxidizing reaction of titanium is much easier than nitriding reaction. The reaction rate of titanium and nitrogen depends on the diffusion rate of nitrogen through the titanium nitride layer. Furthermore, all of the oxides of titanium are more stable than titanium nitride [38]. Although the content of nitrogen in the atmosphere is about $80 \%$, due to the low diffusion rate of nitrogen in titanium and titanium nitride, the reaction between titanium and nitrogen plays a minor role in the process of thermal oxidation of titanium alloy. The higher the temperature, the faster the diffusion rate of the nitrogen is. The titanium nitride is detected on the titanium alloy surface when the temperature is above $800^{\circ} \mathrm{C}$. These results indicate that the reaction between titanium and nitrogen is drastic with the increase of the diffusion rate when the temperature is above $800^{\circ} \mathrm{C}$.

4.3. The Reaction between Oxygen and Aluminum. As illustrated in Figure 9, the absolute value of Gibbs free energy of the reaction between aluminum and oxygen is the largest. The affinity of aluminum and oxygen is greater than the 


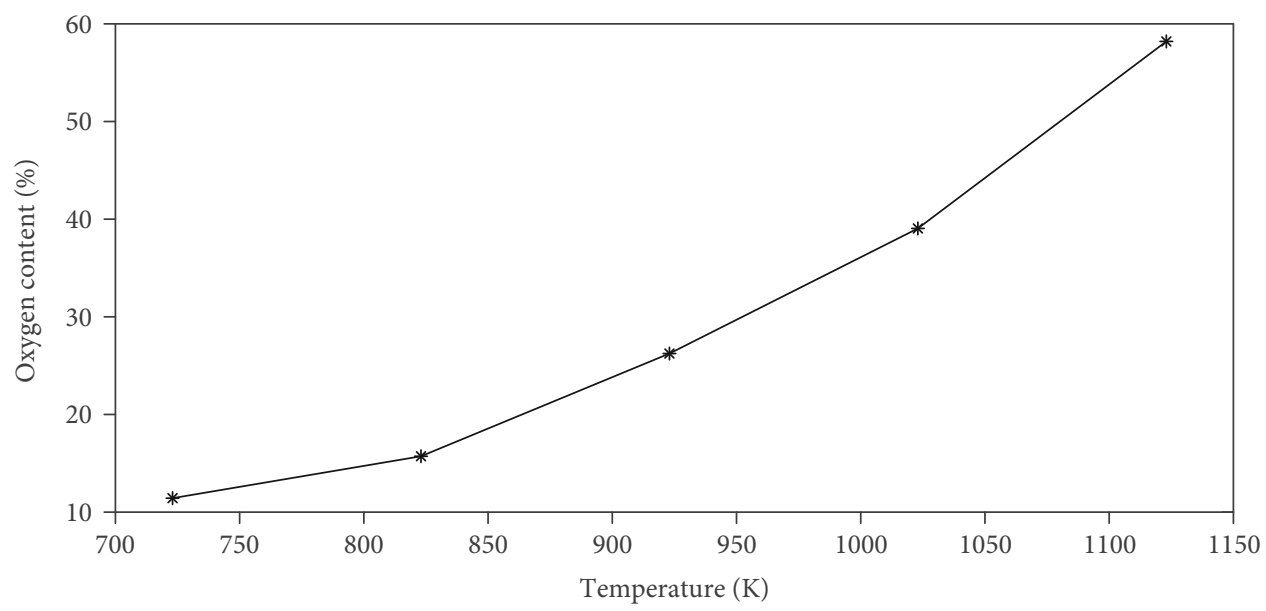

FIgURE 8: Curve of oxygen content at different temperature.

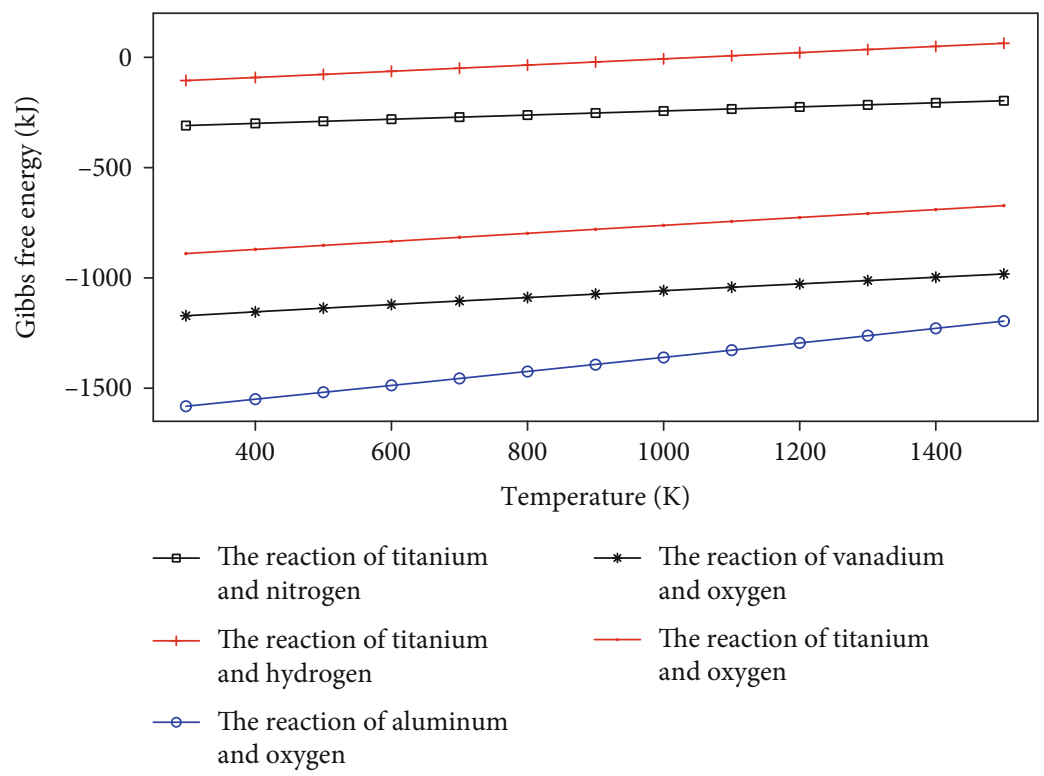

FIgURE 9: Gibbs free energy curves.

affinity of titanium and oxygen, so $\mathrm{Al}_{2} \mathrm{O}_{3}$ is easier to generate. In the early stage of oxidation, the nucleation of $\mathrm{Al}_{2} \mathrm{O}_{3}$ and $\mathrm{TiO}_{2}$ exists on the surface. The growth of $\mathrm{TiO}_{2}$ is faster than $\mathrm{Al}_{2} \mathrm{O}_{3}[40,41]$. Furthermore, $\mathrm{TiO}_{2}$ quickly formed a compact oxidation protective film on the surface of titanium alloy, which prevented the continuous oxidation of aluminum. So, the content of the aluminum element in Ti6Al4V alloy is very low, and $\mathrm{Al}_{2} \mathrm{O}_{3}$ does not affect the oxidation rate of titanium alloys.

4.4. The Reaction between Oxygen and Vanadium. The Gibbs free energy of vanadium reaction with oxygen is smaller than aluminum with oxygen. Similar to the oxygenation of aluminum, the content of vanadium is very small. Other researches have shown that the oxides of vanadium are $\mathrm{VO}_{2}$ and $\mathrm{V}_{2} \mathrm{O}_{5}$ on the surface oxide layer with thermal treatment, and the $\mathrm{V}_{2} \mathrm{O}_{5}$ is the main oxide product [42]. $\mathrm{V}_{2} \mathrm{O}_{5}$ has a low melting point $\left(675^{\circ} \mathrm{C}\right)$ and high saturation vapor pressure. The volatility of $\mathrm{V}_{2} \mathrm{O}_{5}$ is easy to occur under higher temperatures.
Because of the volatilization of $\mathrm{V}_{2} \mathrm{O}_{5}$, the porous oxide layer can be generated on the titanium alloy surface when the temperature is above $700^{\circ} \mathrm{C}[43,44]$. The porous oxide layer has two advantages: on the one hand, it is good for the diffusion of oxygen to the oxide layer, and the oxidation rate increase drastically. Also, it can improve the adhesion, differentiation, and growth of the osteoblast and the biological activity of implants $[45,46]$.

\section{Conclusions}

Based on the analysis of the oxidation mechanism of biomedical titanium alloy and experimental investigation, the following major conclusions can be drawn:

(1) The main oxidation products of titanium alloy Ti6Al4V are $\mathrm{TiO}_{2}$ and a little $\mathrm{Ti}_{3} \mathrm{O}_{5}, \mathrm{Ti}_{2} \mathrm{O}_{3}$, and $\mathrm{TiO}$ when the heating temperature is below $900^{\circ} \mathrm{C}$. At higher temperatures, especially in the condition 
of lower oxygen partial pressure, titanium alloy is more prone to be oxidized to low-valence oxide

(2) The affinity of titanium with oxygen is greater than titanium with hydrogen and nitrogen. Titanium is more prone to react with oxygen. The Gibbs free energy of titanium reaction with hydrogen is a positive value, and the reaction cannot be spontaneous when the temperature is above $650^{\circ} \mathrm{C}$. The reaction between titanium and nitrogen is more prevalent when the temperature is above $800^{\circ} \mathrm{C}$

(3) Although it is much easier for aluminum and vanadium to react with oxygen than titanium, due to the low content and short heating time, the oxide products of aluminum and vanadium make up a small proportion in the resulting oxide layer. $\mathrm{Al}_{2} \mathrm{O}_{3}$ will suppress the oxidation rate of titanium. While the volatilization of $\mathrm{V}_{2} \mathrm{O}_{5}$ will leave porous areas in the oxidation film, it is helpful for titanium oxidation and cell adhesion

(4) Temperature is the main factor that affects the oxidation rate of titanium alloy; the higher the temperature, the greater the oxidation rate and the thickness of oxide film. When the temperature is between $675^{\circ} \mathrm{C}$ and $750^{\circ} \mathrm{C}$, a rapid oxidation rate and the porous $\mathrm{TiO}_{2}$ oxide layer can be obtained. A porous layer can improve the biological activity of implants and enable proper osseointegration

\section{Data Availability}

The data used to support the findings of this study are available from the corresponding author upon request.

\section{Conflicts of Interest}

The authors declare that there is no conflict of interest with any individual/organization for the present work.

\section{Acknowledgments}

This project was funded by the Natural Science Foundation of Shandong Province (ZR2018PEE010) and Ludong University Research Startup Fund (LA2017007).

\section{References}

[1] Y. Han, S. H. Hong, and K. Xu, "Structure and in vitro bioactivity of titania-based films by micro-arc oxidation," Surface and Coatings Technology, vol. 168, no. 2-3, pp. 249-258, 2003.

[2] X. Liu, P. Chu, and C. Ding, "Surface modification of titanium, titanium alloys, and related materials for biomedical applications," Materials Science and Engineering: R: Reports, vol. 47, no. 3-4, pp. 49-121, 2004.

[3] A. Giardini-Guidoni, V. Marotta, R. Teghil, T. M. Di Palma, A. M. Beccaria, and L. Chiaruttini, "Anticorrosion titanium oxide coatings deposited by pulsed laser ablation," Surface and Coatings Technology, vol. 100-101, pp. 437-439, 1998.
[4] F. Zhang, X. Liu, Y. Mao et al., "Artificial heart valves:: improved hemocompatibility by titanium oxide coatings prepared by ion beam assisted deposition," Surface and Coatings Technology, vol. 103, pp. 146-150, 1998.

[5] B. Januszewicz and D. Siniarski, "The glow discharge plasma influence on the oxide layer and diffusion zone formation during process of thermal oxidation of titanium and its alloys," Vacuum, vol. 81, no. 3, pp. 215-220, 2006.

[6] I. Tereshko, V. Abidzina, A. Tereshko, and I. Elkin, "Nanostructural evolution of steel and titanium alloys exposed to glow-discharge plasma," Nuclear Instruments and Methods in Physics Research Section B, vol. 261, no. 1-2, pp. 678-681, 2007.

[7] H. Kawai, Y. Shibata, and T. Miyazaki, "Glow discharge plasma pretreatment enhances osteoclast differentiation and survival on titanium plates," Biomaterials, vol. 25, no. 10 , pp. 1805-1811, 2004.

[8] J. R. Sobiecki, T. Wierzchon, and J. Rudnicki, "The influence of glow discharge nitriding, oxynitriding and carbonitriding on surface modification of Ti-1Al-1Mn titanium alloy," Vacuum, vol. 64, no. 1, pp. 41-46, 2001.

[9] F. Alonso, A. Arizaga, S. Quainton, J. J. Ugarte, J. L. Viviente, and J. I. Oñate, "Mechanical properties and structure of Ti6A1-4V alloy implanted with different light ions," Surface and Coatings Technology, vol. 74-75, pp. 986-992, 1995.

[10] G. Thorwarth, S. Mändl, and B. Rauschenbach, "Rutile formation and oxygen diffusion in oxygen PIII-treated titanium," Surface and Coatings Technology, vol. 136, no. 1-3, pp. 236240, 2001.

[11] Y. Okabe, T. Fujihana, M. Iwaki, and B. V. Crist, "Characterization of oxide layers induced by oxygen ion implantation into $\mathrm{Ti}, \mathrm{V}, \mathrm{Cr}, \mathrm{Zr}, \mathrm{Nb}, \mathrm{Mo}, \mathrm{Hf}$, Ta and W," Surface and Coatings Technology, vol. 66, no. 1-3, pp. 384-388, 1994.

[12] F. Höhl, H. Berndt, P. Mayr, and H.-R. Stock, "Implantation of $\mathrm{N}_{2}^{+}, \mathrm{O}^{+}$and $\mathrm{CO}^{+}$ions into titanium and Ti-6A1-4V," Surface and Coatings Technology, vol. 74-75, no. 1, pp. 765-769, 1995.

[13] C. Hammerl, B. Renner, B. Rauschenbach, and W. Assmann, "Phase formation in titanium after high-fluence oxygen ion implantation," Nuclear Instruments and Methods in Physics Research Section B, vol. 148, no. 1-4, pp. 851-857, 1999.

[14] M. F. Poletika, O. K. Vesnovsky, and K. N. Polestchenko, "Ion implantation for cutting tools," Nuclear Instruments and Methods in Physics Research Section B, vol. 61, no. 4, pp. 446-450, 1991.

[15] J. Been and D. Tromans, "Titanium corrosion in alkaline hydrogen peroxide," Corrosion, vol. 56, no. 8, pp. 809-818, 2000.

[16] Y. Sawada, K. Matsumoto, and T. Katsuki, "Titanium-mediated olefin epoxidation using hydrogen peroxide," Synfacts, vol. 8, p. 0823, 2007.

[17] A. H. Boonstra and C. A. H. A. Mutsaers, "Adsorption of hydrogen peroxide on the surface of titanium dioxide," The Journal of Physical Chemistry, vol. 79, no. 18, pp. 1940-1943, 1975.

[18] P. Tengvall, H. Elwing, L. Sjöqvist, I. Lundström, and L. M. Bjursten, "Interaction between hydrogen peroxide and titanium: a possible role in the biocompatibility of titanium," Biomaterials, vol. 10, no. 2, pp. 118-120, 1989.

[19] J. M. Wu, S. Hayakawa, K. Tsuru, and A. Osaka, "Porous titania films prepared from interactions of titanium with hydrogen peroxide solution," Scripta Materialia, vol. 46, no. 1, pp. 101-106, 2002. 
[20] X. X. Wang, S. Hayakawa, K. Tsuru, and A. Osaka, "Bioactive titania gel layers formed by chemical treatment of Ti substrate with a $\mathrm{H} 2 \mathrm{O} 2 / \mathrm{HCl}$ solution," Biomaterials, vol. 23, no. 5, pp. 1353-1357, 2002.

[21] G. Wang, J. Li, K. Lv et al., "Surface thermal oxidation on titanium implants to enhance osteogenic activity and _in vivo_ osseointegration," Scientific Reports, vol. 6, no. 1, p. 31769, 2016.

[22] L. Li, K. Yu, K. Zhang, and Y. Liu, "Study of Ti-6Al-4V alloy spectral emissivity characteristics during thermal oxidation process," International Journal of Heat and Mass Transfer, vol. 101, pp. 699-706, 2016.

[23] K. J. Ramos-Corella, M. Sotelo-Lerma, A. A. Gil-Salido, J. L. Rubio-Pino, O. Auciello, and M. A. Quevedo-López, "Controlling crystalline phase of $\mathrm{TiO} 2$ thin films to evaluate its biocompatibility," Materials Technology, vol. 34, no. 8, pp. 455-462, 2019.

[24] W. Xue, S. Gao, D. Duan, J. Zhang, Y. Liu, and S. Li, “Ti6Al4V blade wear behavior during high-speed rubbing with NiAlhBN abradable seal coating," Journal of Thermal Spray Technology, vol. 26, no. 3, pp. 539-553, 2017.

[25] Y. Xu, Z. Yao, F. Jia, Y. Wang, Z. Jiang, and H. Bu, "Preparation of PEO ceramic coating on Ti alloy and its high temperature oxidation resistance," Current Applied Physics, vol. 10, no. 2, pp. 698-702, 2010.

[26] M. E. Pätsi, J. A. Hautaniemi, H. M. Rahiala, T. O. Peltola, and I. M. O. Kangasniemi, "Bonding strengths of titania sol-gel derived coatings on titanium," Journal of Sol-Gel Science and Technology, vol. 11, no. 1, pp. 55-66, 1998.

[27] S. C. Dieudonné, J. van den Dolder, J. E. de Ruijter et al., "Osteoblast differentiation of bone marrow stromal cells cultured on silica gel and sol-gel-derived titania," Biomaterials, vol. 23, no. 14, pp. 3041-3051, 2002.

[28] L. Benea and J. P. Celis, "Reactivity of porous titanium oxide film and chitosan layer electrochemically formed on Ti-6Al$4 \mathrm{~V}$ alloy in biological solution," Surface and Coatings Technology, vol. 354, pp. 145-152, 2018.

[29] Y. Wan, T. Wang, Z. Wang, Y. Jin, and Z. Liu, "Construction and characterization of micro/nano-topography on titanium alloy formed by micro-milling and anodic oxidation," The International Journal of Advanced Manufacturing Technology, vol. 98, no. 1-4, pp. 29-35, 2018.

[30] X. Zhu, K. H. Kim, and Y. Jeong, "Anodic oxide films containing $\mathrm{Ca}$ and $\mathrm{P}$ of titanium biomaterial," Biomaterials, vol. 22, no. 16, pp. 2199-2206, 2001.

[31] A. Shanaghi, A. R. Souri, M. Rafie, and P. K. Chu, "Nanomechanical properties of zirconia-alumina-benzotriazole nano-composite coating deposited on Al2024 by the sol-gel method," Thin Solid Films, vol. 689, p. 137417, 2019.

[32] X. J. Tao, S. J. Li, C. Y. Zheng et al., "Synthesis of a porous oxide layer on a multifunctional biomedical titanium by micro-arc oxidation," Materials Science and Engineering: C, vol. 29, no. 6, pp. 1923-1934, 2009.

[33] X. Nie, A. Leyland, and A. Matthews, "Deposition of layered bioceramic hydroxyapatite/TiO2 coatings on titanium alloys using a hybrid technique of micro-arc oxidation and electrophoresis," Surface and Coatings Technology, vol. 125, no. 1-3, pp. 407-414, 2000.

[34] D. L. Ye and J. H. Hu, Handbook of Practical Inorganic Thermodynamic Data ( $2^{\text {nd }} E d$ ), Metallurgical Industry Press, 2002.

[35] C. X. Xu, Foundamental Chemistry, Higher Education Press, 2007.
[36] M. S. Li, High Temperature Corrosion of Metals, Metallurgical Industry Press, 2001.

[37] U. H. Shah, Z. Rahman, K. M. Deen, H. Asgar, I. Shabib, and W. Haider, "Investigation of the formation mechanism of titanium oxide nanotubes and its electrochemical evaluation," Journal of Applied Electrochemistry, vol. 47, no. 10, pp. 11471159, 2017.

[38] N. C. Si and M. X. Fu, Non-ferrous Materials and Preparation, Industry Press, Beijing, 2006.

[39] X. J. Xin, Corrosion of Titanium, Protection and Engineering Application, Anhui Science and Technology Press, 1988.

[40] H. Guleryuz and H. Cimenoglu, "Oxidation of Ti-6Al-4V alloy," Journal of Alloys and Compounds, vol. 472, no. 1-2, pp. 241-246, 2009.

[41] H. L. Du, P. K. Datta, D. B. Lewis, and J. S. Burnell-Gray, "High-temperature corrosion of $\mathrm{Ti}$ and Ti-6Al-4V alloy," Oxidation of Metals, vol. 45, no. 5-6, pp. 507-527, 1996.

[42] M. Hou, Ph.D. A comparative investigation on thermal oxidation of Ti6Al7Nb and Ti6Al4V medical titanium alloys, Zhejiang University, 2010.

[43] A. Ghanbari, F. Warchomicka, C. Sommitsch, and A. Zamanian, "Investigation of the oxidation mechanism of dopamine functionalization in an AZ31 magnesium alloy for biomedical applications," Coatings, vol. 9, no. 9, p. 584, 2019.

[44] M. F. Stroosnijder, N. Zheng, W. J. Quadakkers, R. Hofman, A. Gil, and F. Lanza, "The effect of niobium ion implantation on the oxidation behavior of a $\gamma$-TiAl-based intermetallic," Oxidation of Metals, vol. 46, no. 1-2, pp. 19-35, 1996.

[45] L. J. Gibson and M. F. Ashby, Cellular solids: structure and properties, Cambridge university press, 1999.

[46] L. Chen, K. Wei, Y. Qu et al., "Characterization of plasma electrolytic oxidation film on biomedical high niobium-containing $\beta$-titanium alloy," Surface and Coatings Technology, vol. 352, pp. 295-301, 2018. 